\title{
ENTREVISTA COM PEDRO PAULO ABREU FUNARI: A TRAJETÓRIA DE UM CLASSICISTA BRASILEIRO
}

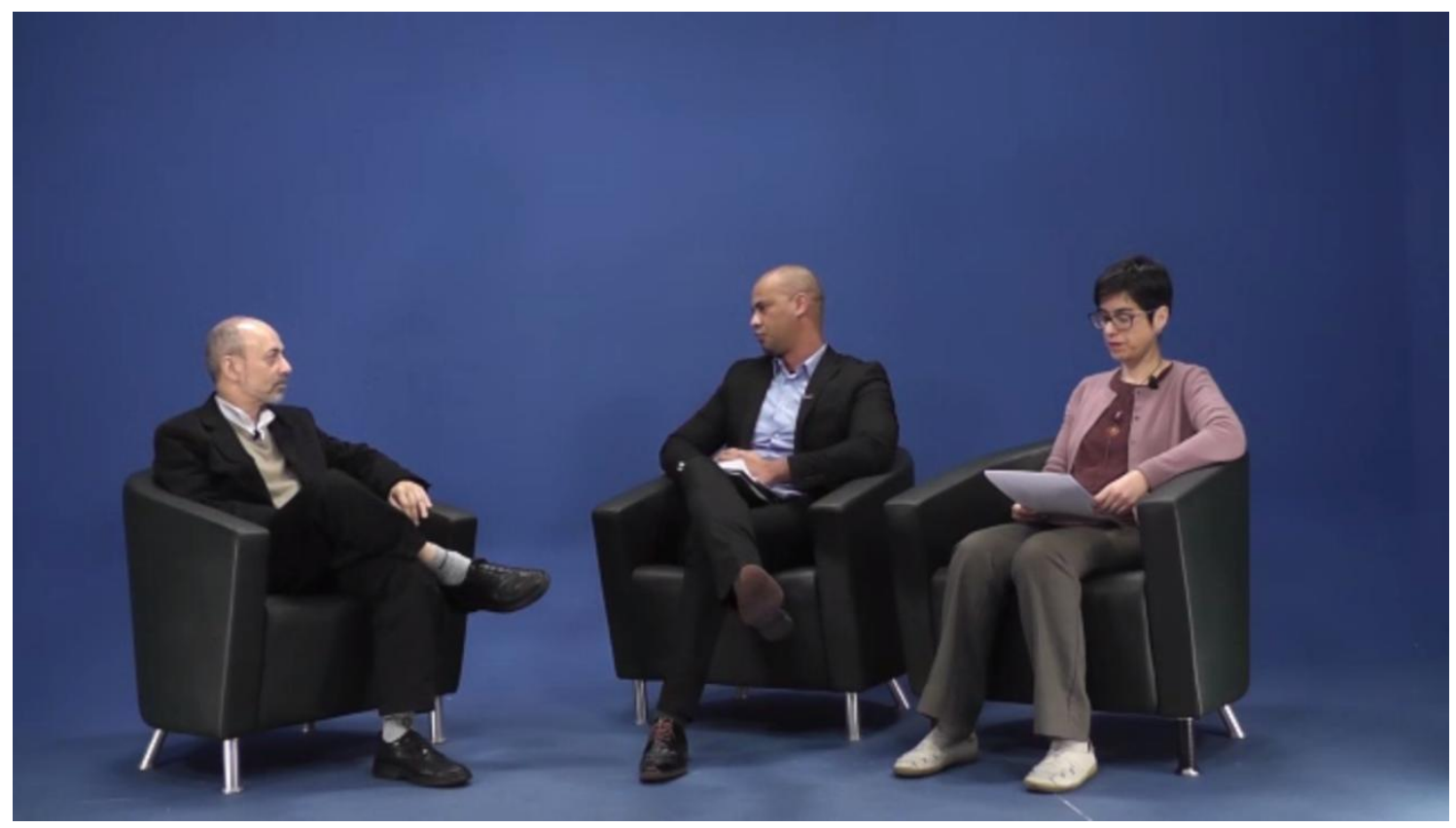

Fig. 1. Entrevista nos estúdios da UNIFESP em 16 de agosto de 2017: à esquerda, Professor Pedro Paulo Abreu Funari (UNICAMP); no meio, Professor Glaydson José da Silva (UNIFESP); à direita, Professora Renata Senna Garraffoni (UFPR).

hiperlink para a entrevista https://www.youtube.com/watch?v=oZd-WVO7JTM

Heródoto (Glaydson José da Silva): Meu nome é Glaydson José da Silva, sou professor de História Antiga do Departamento de História da Universidade Federal de São Paulo (UNIFESP) e editor da revista Heródoto. Para este número da revista, entrevistamos o professor Pedro Paulo Abreu Funari, que é professor titular de História Antiga da Universidade Estadual de Campinas (UNICAMP). Muito obrigado, professor Funari. O professor será entrevistado, nesta ocasião, por mim e pela professora de História Antiga do Departamento de História da Universidade Federal do Paraná (UFPR), Renata Senna Garraffoni. Muito obrigado pela presença, professora Renata. ${ }^{1}$

Começo convidando o nosso entrevistado para uma autorreflexão. O senhor tem uma longa trajetória na área de Estudos da Antiguidade e também da Arqueologia do mundo antigo. Eu gostaria que o senhor nos

\footnotetext{
${ }^{1}$ A entrevista foi transcrita por Erik de Lima Correia, Jemima Novaes Siqueira e Gleice Kelly Freire Delmondes; e sua revisão, por Gilberto da Silva Francisco.
} 
falasse um pouco a respeito de suas escolhas pessoais e profissionais, que o levaram a trilhar esse percurso na área de Estudos da Antiguidade.

Pedro Paulo Abreu Funari: Em primeiro lugar, eu gostaria de agradecer ao Glaydson e à Renata por essa oportunidade e parabenizar a UNIFESP e a Revista Heródoto por essa iniciativa. Bem, eu acho que, muitas vezes, como no meu caso, as pessoas são levadas pelas circunstâncias, e isso foi o que aconteceu comigo: meu interesse foi pela Filosofia Antiga, quando eu estava no colegial e, depois, como não houve possibilidade de estudála, eu fui para a História. Na História eu me interessava por teoria; mas me foi recomendado que seguisse por outros caminhos e eu acabei desembocando, por determinadas circunstâncias, na História Antiga. E, da História Antiga, na Arqueologia Clássica. Então, digamos assim, foram particularidades, circunstâncias.

De qualquer maneira, uma questão de fundo, que eu acho que a pergunta enseja é: por que esse interesse pela Antiguidade? Eu acho que isso tem muito a ver com a formação prévia do imaginário como o meu, em particular, mas também na realidade do brasileiro, na qual havia livros como o do Ceram, Deuses, túmulos e sábios, ${ }^{2}$ um livro feito depois da Segunda Guerra por um alemão muito difundido aqui no Brasil naquela época, e que encantava pelas histórias dos arqueólogos que descobriam o mundo antigo, Tróia, o Mediterrâneo. Então, eu diria que foi uma conjunção de fatores. Mas, uma coisa que eu gosto de chamar a atenção é o fato de que as oportunidades foram surgindo, especificamente na Arqueologia do mundo romano, e eu segui as oportunidades. Depois, outras surgiram e me levaram a outros temas, alguns bastante distantes disso; mas também, por circunstâncias.

Heródoto (Renata Senna Garraffoni): Professor Funari, do ponto de vista acadêmico, quais autores e obras mais influenciaram as suas escolhas?

Funari: Bem, eu acho que seria bom fazer uma divisão de tempo; porque, durante a minha graduação, uma influência muito grande foi a literatura marxista em geral, por exemplo, Althusser, que era um grande nome naquela época, nos anos 1970. Especificamente sobre a Antiguidade, havia uma série de autores franceses como Charles Parain e Monique Clavel-Lévêque, ou russos traduzidos para o alemão, como E. M. Staerman, que me influenciaram muito nesse primeiro período, nos anos 1980.

2 C. Walter Ceram. Deuses, Túmulos e Sábios. São Paulo: Melhoramentos, 1957. 
Depois, eu continuei meus estudos sob o influxo das mudanças, inclusive causadas pelo pós-modernismo, no geral. Isso me levou a uma literatura mais ampla, autores como Paul Veyne, Foucault e mesmo Moses Finley, ligado a uma vertente weberiana. Eu diria que esse é o período de passagem dos anos 1980 para os 1990. Quando, nos anos 1990, eu entrei como docente na UNICAMP, eu diria que fui me direcionando para uma vertente mais pós-moderna literalmente, que seriam questões como identidades múltiplas, a teoria foucaultiana e da diversidade, e da maneira como o passado é construído; que, no caso do mundo antigo, também há autores que vão nessa linha. Então, eu diria que esse é um quadro complexo, porque nenhum autor e nenhuma experiência anterior foram deixados de lado por mim. Acho que vale a pena dizer isso.

Heródoto (Silva): Professor: os gregos, os romanos e nós; os antigos e os modernos; os antigos e os contemporâneos. O que a história da Antiguidade tem a nos dizer sobre o presente? A cultura clássica tem algo a nos dizer para além do lugar da tradição na história do pensamento ocidental?

Funari: Bem, quanto a isso, acho que há duas coisas importantes. Primeiro você citou a tradição. Eu acho que é necessário passar por um repertório, porque, estamos falando de uma cultura que tem como referência valores como democracia, ou mesmo crenças fundadas nela, por exemplo, o Cristianismo, que tem muito a ver com a filosofia grega. Se pensarmos só no Cristianismo, o Evangelho de João, por exemplo, começa basicamente com uma reflexão da filosofia grega. Penso que não é possível evitar a tradição nesse repertório; mas, além disso, como você disse, para além dessa questão do repertório, há uma questão do uso que se faz dele; o que, muitas vezes, é bastante enviesado e visa fins que não são muito claros e podem proporcionar muitas arbitrariedades, muitas injustiças.

Um fator que eu acho importante de se estudar na relação entre esse passado mais distante e o presente é ver como ele tem sido manipulado. Não é possível que não manipulemos (manipular, mexer...); mas, de qualquer maneira, interessa notar como ele tem sido apropriado por grupos sociais, por grupos de interesse. Por exemplo, no uso de Safo por movimentos de libertação feminina ou movimentos de gênero que se referem à Safo, a poetisa grega, há uma clara apropriação; mas é preciso entender como é que as coisas estão, não apenas como um culto à Antiguidade, um culto à Safo; e não é tampouco considerar somente o mundo contemporâneo, há que se considerar o mundo antigo. Outro bom 
exemplo é o movimento espartaquista, na Alemanha no início do século $X X$, que também tem uma inspiração direta na Antiguidade e, portanto, no Espártaco. Então, não é só estudar o Espártaco antigo, nem só o movimento contemporâneo, é mostrar essa dialética.

Heródoto (Garraffoni): Professor, nós abordamos principalmente pontos de vista teóricos; mas também é possível que o público esteja interessado nos inícios de seus estudos, a respeito das escolhas temáticas, e considerando que o senhor tem publicações muito variadas que vão desde a cultura popular grega, passando pelos romanos, também, e o Cristianismo mais inicial, sobre a economia, questões relacionadas ao gênero, sexualidade. Então, o senhor poderia contar um pouco sobre como essas temáticas foram surgindo ao longo da sua pesquisa.

Funari: Esse resumo que você apresentou demonstra que há uma diversidade imensa de temas. Isso se deve, novamente, a duas questões. Uma primeira questão é a circunstância. Eu acho que, como historiadores, essa contingência à circunstância é fundamental, porque muitas vezes nós somos levados. Eu fui levado a temas pela circunstância. Por exemplo, eu comecei a estudar grafites e cultura popular pela circunstância, quando fui convidado a falar sobre. Tive que prestar atenção nisso e, a partir de então, desenvolvi pesquisas sobre o tema. A mesma coisa, eu diria quanto ao tema do gênero. Entrei na UNICAMP como professor, me inseri na área de gênero, de relações de gênero. Então, isso me deu um conjunto de preocupações que eu não tinha originalmente.

Por outro lado, havia outros temas ligados a questões de minha formação, como o Cristianismo, a religiosidade. Havia leituras não só da Bíblia, mas também de outros textos religiosos, por exemplo, os de Ernest Renan, que é um autor do século XIX, um grande estudioso dos fenômenos religiosos, do nacionalismo, que eu já lia antes, como aluno na universidade. Quer dizer, eu comecei a ler isso sem ter um interesse acadêmico, o que só se desenvolveu muito depois. Eu acho que isso é o que serve como uma inspiração, que pode servir como inspiração para os nossos jovens, porque nós temos uma especialização muito precoce na universidade, e é importante que, além dela, a pessoa sempre esteja aberta a outros caminhos.

Heródoto (Silva): Professor, do ponto de vista da formação e da produção intelectual dos historiadores da Antiguidade, quais os limites e 
possibilidades o senhor observa para esses estudiosos seja no Brasil ou seja na Europa?

Funari: Bem, no Brasil, eu acho que a situação é muito favorável. Há poucas décadas, nós tínhamos dificuldade de acesso à documentação, à bibliografia e mesmo às viagens para conhecer e trabalhar em sítios arqueológicos. Hoje em dia, nós temos muitos dos documentos disponíveis, temos praticamente todas as revistas e a possibilidade de viagens é muito ampliada. Então, para o estudante que gostaria de se desenvolver nesta área, há uma situação bastante nova no Brasil; assim como em outras regiões do que se chama Novo Mundo, considerando-se os Estados Unidos, Austrália... Fora da Europa.

E há, além disso, essa questão muito comentada sobre a crise dos clássicos, particularmente em termos da Europa, pelo fato de muitos dos departamentos de latim, grego ou arqueologia clássica de lá terem diminuído; mas acho que isso se deve, em grande parte, às circunstancias e não às permanências. Penso, ao contrário das tendências, que isso volte a ter um enfoque muito importante, pois vejo o interesse em países como o Japão ou a China, que são países de outras tradições, mas têm interesse pela história ocidental e, em particular, pela Antiguidade. Então, eu sou otimista.

Heródoto (Silva): Para os jovens estudiosos, no que se refere ao acesso e às possibilidades hoje, pode-se dizer que são, de fato, muito maiores. Temos praticamente toda a coleção textual publicada em latim-inglês ou latim-francês ou grego-inglês e grego-francês, temos corpus de imagens, corpus epigráficos...; então, para o jovem estudante hoje, o acesso a esses recursos do universo virtual é bem maior e bem mais amplo do que outrora.

Funari: E, além disso, para aprender um idioma hoje em dia, é possível fazer cursos até pelo Skype. Antigamente, era necessário ter o professor presencialmente; então, no fundo, é lógico que isso é sempre contraditório, já que, ao mesmo tempo que há o desenvolvimento tecnológico que evita a mão de obra, produz-se desemprego; mas isso não muda o fato de que o acesso à informação e às possibilidades aumenta a cada dia; apesar dos robôs trabalharem para o ser humano, restam outras atividades, como as aulas dadas por Skype. 
Heródoto (Garraffoni): Neste contexto, você vê essa perspectiva global e a brasileira como favorável atualmente para quem está ingressando na universidade, para quem pensa nos estudos, em se especializar nos estudos da Antiguidade?

Funari: Quanto a isso, eu acho que entramos em uma área difícil, pois vivemos circunstâncias políticas, sociais e econômicas que independem de nós, independem do estudante. Então, é difícil avaliar estas circunstâncias gerais. Mas, do ponto de vista estritamente acadêmico ou profissional, eu acho que as perspectivas são muito boas, pelo seguinte. Primeiro, porque existe um mercado universitário. São universidades do Brasil inteiro que têm a necessidade de especialistas, mas nós temos também escolas com o sistema de ensino médio e básico, cuja ênfase tem sido colocada há décadas.

É necessário, para o país ter uma cidadania consciente e desenvolvimento econômico e que essa população de jovens seja bem formada. É necessário que haja bons professores, que conheçam a história do mundo como um todo e que conheçam também a Antiguidade. E há muitas experiências de uso de textos gregos, tragédias gregas ou comédias latinas no ensino médio e, às vezes, até no ensino fundamental. Há a experiência de escolas em São Paulo onde há aulas de grego, por iniciativa da professora Paula Correia da Universidade de São Paulo (USP), e escolas públicas que têm grego como optativa. Então, resumidamente, eu acho que há um campo muito grande se as pessoas estiverem abertas a essas possibilidades.

Heródoto (Silva): De forma geral, a gente percebe que, para os jovens estudantes hoje, na área de História Antiga, na área de Antiguidade, há um universo de possibilidades que outrora eram desconhecidas. Mas, isso não afasta a necessidade das experiências, no momento de sua formação ou posteriormente, em instituições estrangeiras, como no caso de muitos alunos do senhor.

Funari: Eu penso que isso é parte daquilo que falávamos antes, sobre a inserção dos cientistas brasileiros, especificamente do mundo antigo, em contexto internacional. Há trinta anos, era muito mais difícil para os pesquisadores brasileiros se inserirem internacionalmente. Eram poucos que tinham capacidade e condições, dadas as circunstâncias, de se inserirem em trabalhos no estrangeiro. Hoje em dia, isso é bem mais comum, tanto em trabalhos de campo de Arqueologia, parcerias com professores estrangeiros, ter parte da formação, ou formação integral, no 
estrangeiro. Então, eu creio que isto cria um aspecto antropológico importante, que é a experiência com outros sistemas acadêmicos.

O Brasil é um país muito grande e, portanto, nos relacionamos com o país como que se ele fosse basicamente um universo, que nós precisamos saber só um idioma, nós temos como nos localizar em um país muito grande, temos oportunidades aqui dentro. Entretanto, quando saímos, nós nos enriquecemos. Seja para Argentina, Espanha, França, Inglaterra ou Estados Unidos, Austrália... Nós temos contato com outro tipo de observação sobre o mundo antigo, e percebemos que podemos, inclusive, apresentar contribuições originais, pelo fato de não sermos oriundos apenas de uma tradição; pois, em muitos países de tradição mais antiga, que tem uma tradição secular nesta área, as pessoas seguem a sua própria tradição de uma região ou até mesmo de uma universidade. Então, por força, somos confrontados a esta variedade.

Heródoto (Silva): Gostaria de fazer uma pergunta cuja reflexão é mais detidamente relacionada ao escopo da revista Heródoto (as relações entre o mundo clássico e suas conexões afro-asiáticas). Há uma longa tradição historiográfica que contempla uma miríade, uma variedade muito grande de temas, de estudos sobre a Antiguidade, desde o final do século XIX, sobretudo. Mas, essa tradição historiográfica ainda contempla superficialmente as relações, de forma não hierarquizada, entre o Oriente e o Ocidente. Nesse sentido, a obra do Martin Bernal, ${ }^{3}$ por exemplo, é bastante ilustrativa, ao mostrar as evidências menos hierarquizadas entre essas diferentes tradições. O senhor poderia comentar algo a respeito.

Funari: Penso que, no caso específico de Martin Bernal, houve muitas controvérsias que vocês conhecem muito bem; 4 pois ele era um especialista em China, escrevendo sobre outro tema. Mas, para além dessa controvérsia, eu acho que a questão fundamental é a que você colocou: abrir a Antiguidade para o Oriente, para a África e até para o

\footnotetext{
${ }^{3}$ Martin Bernal. Black Athena: The Afro-Asiatic Roots of Classical Civilization: The Fabrication of Ancient Greece, 1785-1985. Vol. 1. New Brunswick; New Jersey: Rutgers University Press, 1987; Martin Bernal. Black Athena: The Afroasiatic Roots of Classical Civilization. Vol. 2. New Brunswick; New Jersey: Rutgers University Press, 1991; Martin Bernal. Black Athena: The Afroasiatic Roots of Classical Civilization: The Linguistic Evidence. Vol. 3. New Brunswick; New Jersey: Rutgers University Press, 2006.

${ }^{4}$ Para a polêmica, ver, por exemplo, Mary R. Lefkowitz; Guy MacLean Rogers (eds.). Black Athena Revisited. Chapel Hill: University of North Carolina Press, 1996; Martin Bernal; David Chioni Moore (ed.). Black Athena Writes Back: Martin Bernal Responds to His Critics. Durham; London: Duke University Press, 2001.
} 
Extremo Oriente. Muitas vezes, no passado, esqueceu-se justamente dessas relações, seja com o Egito especificamente, que eu acho que o Martin Bernal explora muito bem - as origens egípcias e uma série de laços culturais. E mesmo com o Oriente é impossível desvencilhar, por exemplo, a Antiguidade, a partir de um determinado momento, da Índia. E ninguém pensa na Índia quando se fala de cultura helenística; a cultura desse período grande que começa no século terceiro antes de Cristo, e vai até o período romano todo. Mesmo o Cristianismo, por exemplo, no evangelho de João, é realmente impossível desvencilhar da filosofia grega, que também não pode se desvencilhar do Oriente.

Eu penso que a questão de fundo é que, muitas vezes, os Estudos Clássicos foram utilizados de um ponto de vista reacionário, para a defesa da ordem, das relações estabelecidas, das relações hierárquicas e de dominação em relação aos povos coloniais. Então, isso marcou muito a disciplina. Há obras muito conservadoras. Inclusive, na teoria, muito atrativas na aparência, mas muito conservadoras, como, por exemplo, a Paideia de Jaeger, ${ }^{5}$ que apresenta uma visão muito idealizada, e que foi instrumentalizada pela direita. Entretanto, concluindo, eu diria que a Antiguidade pode servir para o contrário, iluminar certos aspectos e ir mais distante, como você citou, ir ao Oriente, ir à África, e não ficar só com uma falsa ideia de autoctonia dessa cultura ocidental, já que isso não existe.

Heródoto (Silva): Outro aspecto importantíssimo, a meu ver, da obra de Martin Bernal, é o fato de chamar a atenção para como os antigos viam a sua própria história, para como os gregos viam a sua história como enormemente tributária de culturas do Norte da África, da cultura egípcia; ele chama a atenção para um aspecto comumente olvidado, comumente negligenciado nos estudos historiográficos e que é retomado no contexto da produção da sua obra, cujo próprio título é bastante instigante: o nome Black Athena: raízes afro-asiáticas da civilização ocidental, o título é, em si, uma enorme provocação.

Funari: Exatamente. Você diz muito bem. As próprias obras antigas são lidas muitas vezes já com preceitos que não têm nada a ver com os povos antigos. Então, somos modernos. Voltamos àquela questão da relação contemporâneo-antigo. É impossível você ter acesso à Antiguidade sem passar pelos momentos posteriores, principalmente os séculos XIX e XX. Isso quer dizer que a leitura sobre o passado foi muito enviesada. Um

\footnotetext{
${ }^{5}$ Werner Jaeger. Paideia: a formação do homem grego. São Paulo: Martins Fontes, 1994.
} 
exemplo clássico que a gente poderia indicar é o caso da sexualidade. Os antigos eram diferentes. Em qualquer período histórico, as pessoas eram diferentes. Quanto à Antiguidade, isso significa dizer que se fez, no passado recente, aproximações completamente anacrônicas a respeito deles. No que se refere à sexualidade, demorou-se muito para se tratar desse tema e imaginar que isso pudesse ser discutido como hoje em dia. Por muito tempo, esse era um tema que não aparecia, que não existia. Em grande medida, a mesma coisa ainda está para ser feita com relação às culturas orientais e africanas. Eu acho que, como disse, essa preocupação vem do XIX, muitos autores do XIX estavam preocupados com essa ligação com o Oriente, pelo fascínio da Índia, da China, mas particularmente da Índia, então houve uma série de aproximações, mas ainda são temas minoritários na historiografia sobre o mundo antigo.

Heródoto (Garraffoni): Essas considerações são importantes para que a gente possa pensar um pouco a respeito do ofício do historiador. Como ele está tratando a teoria, a documentação e, de certa maneira, as formas que a gente mobiliza na relação do passado com o presente. Então, acredito que esse tipo de reflexão seja fundamental dentro da proposta da própria revista. Você gostaria de comentar alguma coisa a respeito?

Funari: Sobre isso, é preciso dizer o seguinte: nós temos, felizmente, um número maior de revistas no Brasil, inclusive sobre o mundo antigo. Mas, a originalidade da revista Heródoto, que eu acho que deve ser ressaltada, é justamente essa ênfase na heterodoxia. Ir além e buscar essa ligação entre o passado e presente, essa ligação entre o Oriente, Ocidente e a África. Eu acho que isso é uma grande novidade e eu dou os parabéns para a UNIFESP também nesse aspecto.

Heródoto (Silva): Eu gostaria, para encerrar, de retomar a fala que o senhor fez agora, com uma última questão. Agora pouco, o senhor comentou algo sobre como o passado é recebido e, na fala da professora Renata, também aparece essa mesma questão. Vemos vigorar hoje no país uma longa tradição que tem se estabelecido sobre os usos do passado, que outrora não eram entendidos como História da Antiguidade, e hoje passam a ser acolhidos, entendidos dentro de uma nova perspectiva, questões que eram colocadas por historiadores brasileiros da Antiguidade que trabalhavam nessa perspectiva, e que não foram colocadas por historiadores de outras tradições historiográficas. Sobre isso, o senhor pode nos esclarecer um pouco mais a respeito do seu 
entendimento sobre recepção, usos do passado, se há distinção entre recepção, usos e apropriação do passado.

Funari: Esse é um tema amplo, mas eu diria que, pra ser bem sucinto, eu penso que a recepção, que é um termo muito utilizado na língua inglesa, ele enfatiza muito a ideia de algo original, de um lado, e recebido no mundo contemporâneo. $\mathrm{O}$ mundo contemporâneo recebe algo que veio do antigo. Em minha opinião, a ideia de usos do passado tem uma nuance um pouco diferente, pois parte da ideia de que estamos no presente usando o que veio antes, para formular algo. É quase inevitável que estejamos fazendo isso, mas não é só uma recepção, como na Física, como com o som: você emite um som e o outro recebe o som na orelha... Não é isso. Ao contrário, é toda uma constante relação de interpretação. Quando nós ouvimos, há a interpretação do que estamos ouvindo. Não é possível apenas receber. Então, depende um pouco do que entendemos por recepção; se formos entender no sentido mais amplo, eu acho que ela se coaduna bem com os usos do passado.

Heródoto (Silva): Eu gostaria de agradecer muitíssimo ao professor Funari, que gentilmente nos concedeu esta entrevista, nesta ocasião, a mim e à professora Renata Senna Garraffoni, que participou deste momento colocando questões que interessam a todos. Muito obrigado, professora Renata; muito obrigado, professor Funari. 